\title{
Traditional Chinese Medicine and Herb-induced Liver Injury: Comparison with Drug-induced Liver Injury
}

\author{
Jing Jing ${ }^{1,2}$ and Rolf Teschke*3 \\ ${ }^{1}$ Medical School of Chinese PLA, Beijing, China; ${ }^{2}$ Integrative Medical Center, 302 Military Hospital, Beijing, China; ${ }^{3}$ Department of \\ Internal Medicine II, Division of Gastroenterology and Hepatology, Klinikum Hanau, Teaching Hospital of the Medical Faculty of the
} Goethe University, Frankfurt/Main, Germany

\begin{abstract}
Cases of suspected herb-induced liver injury (HILI) caused by herbal Traditional Chinese Medicines (TCMs) and of druginduced liver injury (DILI) are commonly published in the scientific literature worldwide. As opposed to the multiplicity of botanical chemicals in herbal TCM products, which are often mixtures of several herbs, conventional Western drugs contain only a single synthetic chemical. It is therefore of interest to study how HILI by TCM and DILI compare with each other, and to what extent results from each liver injury type can be transferred to the other. China is among the few countries with a large population using synthetic Western drugs as well as herbal TCM. Therefore, China is well suited to studies of liver injury comparing drugs with TCM herbs. Despite some concordance, recent analyses of liver injury cases with verified causality, using the Roussel Uclaf Causality Assessment Method, revealed major differences in HILI caused by TCMs as compared to DILI with respect to the following features: HILI cases are less frequently observed as compared to DILI, have a smaller proportion of females and less unintentional rechallenge events, and present a higher rate of hepatocellular injury features. Since many results were obtained among Chinese residents who had access to and had used Western drugs and TCM herbs, such ethnic homogeneity supports the contention that the observed differences of HILI and DILI in the assessed population are well founded.
\end{abstract}

Citation of this article: Jing J, Teschke R. Traditional Chinese medicine and herb-induced liver injury: comparison with druginduced liver injury. J Clin Transl Hepatol 2018;6(1):57-68. doi: 10.14218/JCTH.2017.00033.

Keywords: Traditional Chinese medicine (TCM); Herbal TCM hepatotoxicity; Herb-induced liver injury (HILI); Roussel Uclaf Causality Assessment Method (RUCAM); Drug-induced liver injury (DILI).

Abbreviations: ALF, acute liver failure; ALP, alkaline phosphatase; ALT, alanine aminotransferase; APCs, antigen presenting cells; AST, aspartate aminotransferase; CAMs, causality assessment methods; CHM, Chinese herbal medicine; $\mathrm{CI}$, confidence interval; DILI, drug-induced liver injury; DILIN, Drug-Induced Liver Injury Network; HDS, herbal and dietary supplements; HEV, hepatitis E virus; HILI, herb-induced liver injury; HM, herbal medicine; HR, hazard ratio; HSOS, hepatic sinusoidal obstruction syndrome; INR, international normalized ratio; LTs, liver tests; MeSH, Medical subject headings; MV, Maria and Victorino; NA, not available; NAPQI, N-acetyl-p-benzoquinone imine; PA, pyrrolizidine alkaloid; RUCAM, Roussel Uclaf Causality Assessment Method; SD, standard deviation; TB, total bilirubin; TCM, traditional Chinese medicine; UK, United Kingdom; ULN, upper limit of normal; WHO, World Health Organization; WM, Western medicine. Received: 17 May 2017; Revised: 24 August 2017; Accepted: 28 August 2017 *Correspondence to: Rolf Teschke, Department of Internal Medicine II, Klinikum Hanau, Teaching Hospital of the Goethe University of Frankfurt/Main, Leimenstrasse 20, Hanau D-63450, Germany. Tel: +49-6181-21859, Fax: +49-6181-2964211, E-mail: rolf.teschke@gmx.de

\section{Introduction}

Suspected cases of herb-induced liver injury (HILI) caused by Traditional Chinese Medicines (TCMs) have been highlighted in many publications on case reports and case series or have received commentaries and analyses in review articles. ${ }^{1-12}$ These reports have been published by groups from many countries ${ }^{5,12}$ and have implied that herbal TCMs are potential therapeutic options of worldwide importance. ${ }^{5}$ Such a worldwide distribution pattern of herbal TCM use also suggests that liver injury by TCM herbs likely emerges in all ethnic populations and lacks major predisposition features based on ethnic factors. Based on a unique traditional theory, herbal TCM has a long history of use in clinical practice, especially in Asian countries, including China. ${ }^{5}$

Consumers and herbalists commonly believe that herbal TCMs and other herbal medicine (HM) products labeled as "natural" are always safe and of benefit to public health, improving physical fitness, extending lifespan, and treating various illnesses. Thus, and as expected, it seems that the global consumption of herbal TCM products has rapidly expanded, although valid data are sparse. ${ }^{5}$ Concomitantly, liver injury cases associated with TCM use have increasingly been published in the last few years. ${ }^{12}$ This is at variance with previously published and recently confirmed results of clinical studies in a German TCM hospital; under strict in-patient conditions, the use of herbal TCMs was evaluated for possible increases of liver tests (LTs). ${ }^{7,8}$ In only $0.3 \%$ of all treated patients, liver injury newly emerged with a merely possible causality grading as assessed by the Roussel Uclaf Causality Assessment Method (RUCAM). ${ }^{5,8}$

The abundance of reported liver injury cases in connection with the use of herbal TCMs is a clinical and scientific challenge, as various aspects are under critical discussion. ${ }^{1-12}$ There are questions of incidence and prevalence rates, issues of herbal product quality, clinical course and validity of applied causality assessment methods (CAMs), as well as pathogenetic considerations. Most of these topics have also been studied in patients with liver injury caused by synthetic Western drugs. ${ }^{13-15}$ It is therefore of interest how HILI by TCMs and drug-induced liver injury (DILI) compare with each other, and to what extent the results from each liver injury type can be transferred to the other. China is among the few countries with a large population using synthetic Western drugs, herbal TCM, or both together. Therefore, China is well suited to studies of liver injury comparing drugs with TCM herbs. ${ }^{1}$

In the present review article, we focus on characteristic clinical features and outcomes of patients with HILI caused by 
Jing J. et al: Traditional Chinese medicine for liver injury

herbal TCMs as compared to DILI, as well as the use of potential diagnostic biomarkers and issues of other diagnostic approaches. Special attention is paid to CAMs for liver injury cases, considering RUCAM (specifically, its update of 2016), the most commonly used CAM ${ }^{16}$ and other CAMs (including expert opinion-based ones), which are briefly evaluated regarding the advantages and limitations of their use.

\section{Search strategy}

\section{Search and identification terms}

The PubMed database was searched to identify publications such as clinical trials and review articles using the following terms: medical subject headings (MeSH) term "medicine, Chinese traditional", "drugs, Chinese herbal", "herbal medicine", or their entry terms; these terms were combined with hepatotoxicity, liver injury or liver diseases, MeSH terms "chemical and drug-induced liver injury" or its entry terms such as "chemically-induced liver toxicity", "toxic hepatitis". This led to the identification of publications of herbs combined with their MeSH terms and entry terms, with hits of around 3837 or 14,160 , respectively; for liver injury combined with herbs, 59 or 282 hits were presented. Meanwhile, publications of DILI were identified on the PubMed database with the MeSH term or its entry terms, which provided 26,448 hits. Among the publications in each category, the first 100 hits were commonly considered. The literature provided by PubMed covered the years 1996 to 2016.

\section{Data analysis}

Publications were analyzed for their scientific and clinical value, data quality and relevance related to the topic of this article. Publications of good quality were preferred and considered for evaluation. Publications in the English language were preferred, but some important studies published in Chinese language were also included in the analysis. Literature in English was rarely provided since essential HILI publications, especially those related to herbal TCMs, were in foreign languages of the Eastern countries, including Chinese, Korean and Japanese, lacking an English abstract. Therefore, publications in English, Chinese and other Asian languages were collected in our present review article. A manual search focused on reports not yet identified. The literature search ended on 31 December 2016.

Epidemiology of overall liver injury cases

\section{Incidence}

Data on firm incidence rates of HILI caused by TCM products in the general population are limited, due to a lack of prospective large-sale studies in individuals with excluded chronic or acute liver diseases prior to therapy initiation with herbal TCMs. However, to provide some order of magnitude, in $3 / 994$ individuals $(0.3 \%)$ from Germany, liver injury with a RUCAM-based possible causality level was described as a consequence of herbal TCM use; ${ }^{5,7}$ none of the 994 individuals received a probable or highly probable RUCAM-based causality grading, while 3 experienced clinically irrelevant liver adaptation with alanine aminotransferase $(A L T)<5 \times$ upper limit of normal (ULN). Among the study cohort, the most frequent adverse reactions included gastrointestinal symptoms (13.4\%), neuro-vegetative symptoms $(6.1 \%)$ and diarrhea $(4.6 \%))^{5,7}$ The lack of substantial liver injury by herbal TCM products shown under strict hospital conditions is indeed unexpected and needs confirmation. Under normal field conditions outside of a hospital setting, more cases of HILI from various TCM herbs were published with established causality of higher gradings, as assessed by RUCAM, positive re-challenge tests, or both. ${ }^{5}$

For DILI, a crude incidence rate of $2.4 \pm 0.4$ per 100,000 person-years was reported from $\mathrm{UK}_{1}{ }^{17}$ an overall annual incidence of $34.2 \pm 10.7$ cases per $1,000,000$ inhabitants from Spain, ${ }^{18}$ a crude annual global rate of $13.9 \pm 2.4$ per 100,000 inhabitants from France, ${ }^{19}$ and an overall annual incidence of $19.1 \pm 4.3$ per 100,000 inhabitants from Iceland ${ }^{20}$ (Table 1 ). It is noteworthy that the incidence data of HILI caused by herbal medicines including TCMs and herbal dietary supplements cannot be determined due to a lack of such published cohort studies

\section{Prevalence}

Prevalence data of HILI cases specifically due to herbal TCMs' use are limited, since reliable clinical and epidemiological studies are lacking. ${ }^{6}$ Global prevalence of unspecified HILI

Table 1. Epidemiology data of drug-induced liver injury

\begin{tabular}{|c|c|c|c|c|c|c|}
\hline Study ${ }^{\text {Ref }}$ & Country & Period & Patients, $n$ & Population, $n$ & Database & Incidence (95\% CI) \\
\hline $\begin{array}{l}\text { de Abajo } \\
\text { et al. }{ }^{17}\end{array}$ & UK & $\begin{array}{l}1994 / 1 / 1- \\
1999 / 12 / 31\end{array}$ & 128 & 1636792 & $\begin{array}{l}\text { UK-based General } \\
\text { Practice Research } \\
\text { Database }\end{array}$ & $\begin{array}{l}2.4 \text { per } 100,000 \\
\text { person-years }\end{array}$ \\
\hline $\begin{array}{l}\text { Andrade } \\
\text { et al. }{ }^{18}\end{array}$ & Spain & $\begin{array}{l}1994 / 4- \\
2004 / 8\end{array}$ & 461 & $\mathrm{~N} / \mathrm{A}$ & $\begin{array}{l}\text { Regional Registry of } \\
\text { Hepatotoxicity in } \\
\text { Southern Spain }\end{array}$ & $\begin{array}{l}34.2 \pm 10.7 \\
\text { per } 1000000 \\
\text { inhabitants per year }\end{array}$ \\
\hline $\begin{array}{l}\text { Sgro } \\
\text { et al. }{ }^{19}\end{array}$ & France & $\begin{array}{l}1997 / 11 / 5- \\
2000 / 11 / 4\end{array}$ & 34 & 81301 & $\begin{array}{l}\text { Regional capital located } \\
\text { in the rural French } \\
\text { administrative } \\
\text { Department of Nievre }\end{array}$ & $\begin{array}{l}13.9 \pm 2.4 \text { per } \\
100000 \text { inhabitants }\end{array}$ \\
\hline $\begin{array}{l}\text { Björnsson } \\
\text { et al. } 20\end{array}$ & Iceland & $\begin{array}{l}2010 / 3 / 1- \\
2012 / 2 / 29\end{array}$ & 96 & 251000 & $\begin{array}{l}\text { Directorate of Health } \\
\text { in Iceland }\end{array}$ & $\begin{array}{l}19.1 \pm 4.3 \text { per } \\
100000 \text { inhabitants }\end{array}$ \\
\hline
\end{tabular}

* The estimated annual incidence of hepatotoxicity at the coordinating center was from 1998 to 2003. Abbreviations: CI, confidence interval; N/A, not available; UK, United Kingdom. 
Jing J. et al: Traditional Chinese medicine for liver injury

Table 2. Percentage of HILI cases among DILI/HILI cohorts in Asian countries

\begin{tabular}{|c|c|c|c|c|}
\hline Study ${ }^{\text {Ref }}$ & Country & Period & Overall DILI/HILI cases, $n$ & HILI cases, $\%$ \\
\hline Takikawa et al. ${ }^{27}$ & Japan & $1997 / 1-2006 / 12$ & $1676 / 64$ & 3.8 \\
\hline Wai et al. ${ }^{28}$ & Singapore & $2004 / 6 / 1-2006 / 7 / 1$ & $22 / 13$ & 59 \\
\hline Lee et al. ${ }^{29}$ & Korea & $2003 / 7-2013 / 2$ & $65 / 28$ & 43.1 \\
\hline Zhu et al. ${ }^{1}$ & China & $2009 / 1-2014 / 1$ & $1985 / 563$ & 28.4 \\
\hline
\end{tabular}

In the study of Wai et al. ${ }^{28}$ of $17 \mathrm{HILI}$ cases, liver injury was caused by Chinese traditional complementary and alternative medicine.

Abbreviations: DILI, drug-induced liver injury; HILI, herb-induced liver injury.

could be considered if all herbs contained in herbal drugs and herbal dietary supplements were included, whereas a specific prevalence rate refers to one single herb. The prevalence of liver injury caused by HMs was evaluated by a single-center study of liver injury in Korea. ${ }^{21}$ In this study of 1,169 patients, liver injury attributable to HMs was observed in five patients $(0.43 \%)$, compared with five other patients with liver injury due to Western medicine (WM) ${ }^{21}$ True prevalence data are lacking for unspecified $\mathrm{HILI}^{22,23}$ and herbal and dietary supplements (HDSs). ${ }^{24,25}$

For liver injury caused by synthetic drugs, some prevalence data are available from a Korean retrospective analysis of 1,169 cases, which found 11 DILI cases $(0.94 \%) .{ }^{21}$ In 6-week survey studies from 30 German pharmacies between 2011 and 2012, an unexpected high prevalence of DILI in pharmacy customers was reported, since, in 141 out of 1,098 patients $(12.8 \%)$, elevated liver enzymes caused by suspected synthetic drugs were found. ${ }^{26}$ Prevalence rates of DILI in Korea were significantly different from those in Germany, likely because of small sample sizes and region limitation. Additionally, describing the valid epidemiological features of specific liver injury cases requires a clear differentiation of herbal TCMs from synthetic drugs and more data from multi-center, controlled studies, as opposed to the present prevailing conditions reporting cases of DILI and HILI by TCMs together (Table 2). In most of these liver injury studies, HILI cases were less frequently observed as compared to DILI cases. ${ }^{1,27-29}$ This discrepancy is best explained by a higher use of synthetic drugs, as compared to herbal products, among the assessed cohorts.

\section{Constituent ratio of HILI in DILI/HILI cohorts}

Some liver injury reports include DILI and HILI cases in their study cohorts and provide valuable information on constituent ratios, which differ from country to country (Table 2 ). In a retrospective analysis of 1,676 Japanese patients with liver injury in 1997-2006, herbal TCMs were implicated as causes in about $3.8 \%$ of cases. ${ }^{27}$ In a prospective study from Singapore, Chinese herbs were responsible for the symptoms of 31 patients (55\%) among those who were diagnosed with liver injury at a tertiary hospital over a 26 -month period. ${ }^{28}$ In a single-center retrospective analysis from Korea during 2003 to 2013, the major causative agents among the DILI/HILI cohort were HMs $(43.1 \%)$, prescription medications $(21.6 \%)$, and traditional therapeutic preparations or dietary supplements (35\%). ${ }^{29}$ Among 899 DILI/HILI patients in a study from the United States, 145 patients (16.1\%) with liver injury were associated with the use of HDSs. ${ }^{30,31}$ In a retrospective analysis of a liver injury cohort consisting of 1,985 DILI/HILI patients from the Military Hospital in Beijing between 2009 and 2014, 563 patients (28.4\%) were diagnosed with HILI caused by herbal TCMs.

The causes of the constituent ratio variability of HILI by TCMs among liver injury cohorts from different countries are unknown but likely due to several factors. First, people's unique living habits and cultural conventions when deciding on medications are different among countries and regions. Second, differences in survey and research conditions may be contributory, such as single-center versus multi-center studies, or prospective versus retrospective analyses. Third, conformity of medical diagnostic categorizations and their statistical methods was not provided. The existence of over different 10,000 Chinese herbal drugs within many subcategories complicates any comparison between the variable Chinese herbs with single well-defined synthetic drugs. ${ }^{1,32}$

\section{Demographics}

The median age of 839 patients with liver injury caused by HDSs and synthetic drugs was 50 years in a study from the United States (Table 3). ${ }^{31}$ Similarly, a mean age of 46.1 years was reported for 8,528 patients with HILI by TCMs, based on 127 publications provided by the Chinese Periodical Full-text Database. ${ }^{33}$ This was similar to a single-center retrospective analysis in China, which showed that the patient group with HILI caused by TCMs was aged from 41 to 50 years, with an average of 46.1 years. ${ }^{1,33}$ In the United States, the mean age of patients with DILI/HILI was $49 \pm 17$ years among 899 patients. ${ }^{30}$ A compilation of these data is presented in Table 3.

Uncertainty exists whether sex is a risk factor of liver injury. ${ }^{34,35}$ At least in China, women are less likely to experience HILI and DILI than men, as evidenced by two retrospective analyses. ${ }^{33,36}$ This is at variance to the United States, where DILI is more common in female patients than in males, with a preponderance of females for the hepatocellular type of liver injury. ${ }^{30,37}$ The higher susceptibility of women for DILI is unclear but could be ascribed to differences in drug pharmacokinetics, specific hormonal effects, and adverse immune reactions to some drugs. ${ }^{35}$ The sex distribution is shown in Table 3.

\section{Complexity of liver injury pathogenesis}

Liver injury is caused by an idiosyncratic or intrinsic reaction. ${ }^{5,14-16}$ Only idiosyncratic liver injury occurs largely independently of the applied dose and emerges unpredictably, as opposed to intrinsic liver injury, which does not share these characteristics. ${ }^{5}$ This contributes to the complexity of pathogenetic aspects related to idiosyncratic HILI and idiosyncratic DILI. ${ }^{5,14,15}$ Although firm evidence is lacking due to the unavailability of appropriate studies in patients, two mechanistic 
Jing J. et al: Traditional Chinese medicine for liver injury

Table 3. Demographic data in retrospective and prospective DILI/HILI case studies

\begin{tabular}{|c|c|c|c|c|c|c|c|}
\hline \multirow[b]{2}{*}{ Study ${ }^{\text {Ref }}$} & \multirow[b]{2}{*}{ Published time } & \multirow[b]{2}{*}{ Country } & \multicolumn{2}{|c|}{ Overall cases of DILI } & \multicolumn{2}{|c|}{ HILI cases by HMs/HDSs } & \multirow[b]{2}{*}{ Age $^{*}$} \\
\hline & & & Patients, $n$ & $M / F, \%$ & Patients, $n$ & $M / F, \%$ & \\
\hline Wu et al. ${ }^{33}$ & 2008 & China & 12915 & $57.8 / 42.2$ & 2026 & $51 / 49$ & $46.1^{\S}$ \\
\hline Navarro et al. ${ }^{31}$ & 2015 & United States & 847 & $40 / 60$ & 130 & $58 / 42$ & 50 \\
\hline Zhu et al. ${ }^{1}$ & 2016 & China & 1985 & $40 / 60$ & 563 & $29 / 71$ & $44 \pm 15$ \\
\hline Chalasani et al. ${ }^{30}$ & 2016 & United States & 899 & $41 / 59$ & 145 & N/A & $49 \pm 17$ \\
\hline
\end{tabular}

* In the four studies, the reported ages refer to all patients with DILI and HILI caused by HMs. Age is given as mean \pm SD, or as median.

${ }^{\S}$ The mean age was analyzed in 8528 cases from 127 references.

Abbreviations: DILI, drug-induced liver injury; HILI, herb-induced liver injury; HMs, herbal medicines; HDSs: herbal and dietary supplements; N/A, not available; SD, standard deviation.

hypotheses for the initiation and progression events are under discussion for idiosyncratic liver injury: first, sterile inflammation caused by drug-induced cytotoxicity; second, immune response via antigen presenting cells (APCs) and/or helper T-cells. ${ }^{38}$ Moreover, product properties and host factors could play a key role in different functional pathways, individual susceptibility, clinical phenotype, and outcome. ${ }^{38}$

\section{HILI by TCMs}

HILI caused by TCMs is mostly of the idiosyncratic type of liver injury, rarely of the intrinsic or undetermined type. ${ }^{5}$ Idiosyncratic liver injury cannot be reproduced in experimental animals, which precludes toxicological studies in order to clarify pathogenetic sequences that lead to liver cell apoptosis and cell death. Nevertheless, and despite these methodological uncertainties and study limitations, some publications claim having identified, for some TCM herbs, specific chemical ingredients as causative agents for liver injury, referring most likely to the intrinsic type. ${ }^{38,39}$ For instance, anthraquinones and $2,3,5,4^{\prime}$-tetrahydroxy trans-stilbene-2-O- $\beta$-glucoside are proposed as the hepatotoxic components for Polygonum multiflorum Thunb, ${ }^{40,41}$ volatile oils for Artemisia argyi (Ai Ye), ${ }^{42,43}$ toxic proteins (ricin) for Rhicinus communis (Bi Ma Zi), ${ }^{44}$ glycosides (kaurene) and diterpenoids for Xanthium (Cang Er Zi), ${ }^{45}$ alkaloids (dichroine) for Dichor febrifuga Lour (Chang Shan), ${ }^{46}$ glycosides (saponine) for Albizia julibrissin (He Huan Pi), ${ }^{47}$ glycosides (steroids, diosgenin) and diterpenoids-lactones for Discorea bulbifera $L$ (Huang Yao Zi) ${ }^{48,49}$ glycosides (tetranortriterpenoids) for Melia azedarach (Ku Lian Zi), ${ }^{50}$ glycosides (tripterygium), diterpenoid-lactones for Tripterygium wilfordii hook $F$ (Lei Gong Teng), ${ }^{51}$ alkaloids (phytolaccine) for Phytolacca acinosa Roxb. (Shan Lu), ${ }^{52}$ or toxic proteins (abrin) for Abrus Precatorius (Xiang $\mathrm{Si} \mathrm{Zi}$ ). ${ }^{53}$ Although such examples were reported as culprits of various cases of liver injury by herbal TCMs, the potential hepatotoxicity of these chemical ingredients from most of the herbal TCMs is unknown. $5,54,55$

The intrinsic types of HILI due to TCMs are mostly caused by herbs with unsaturated pyrrolizidine alkaloids (PAs) as their ingredients and hepatotoxic culprits. ${ }^{56-58}$ A series of experimental and comparative studies with Jing Tian San Qi (Sedum aizoon, syn. Stonecrop) and the TCM herb Shan Chi (Gynura segetum) have provided clear evidence that the PAcontaining Shan Chi is the herb responsible for many cases of hepatic sinusoidal obstruction syndrome (HSOS), previously called hepatic veno-occlusive disease. ${ }^{10,59}$ PA-containing TCM herbs, such as Shan $C^{10,59}$ or Senecio vulgaris $L^{100}$ preferentially injure the sinusoidal endothelial cells of the liver and thereby reduce the blood flow within the sinusoids. ${ }^{4,61}$ One of the first TCM herbs causing intrinsic liver injury was the TCM Shi Can. This consists of Teucrium chamaedrys or other Teucrium species and is better known in Western countries as Germander. ${ }^{62}$ Although liver injury by Germander was mostly low-graded and transient, this hepatotoxic herb has been taken off the French HM market. ${ }^{5,62,63}$

Because human PA-induced HILI is well reproducible in animals, such models have been used widely to clarify the pathogenetic aspects of liver injury, with its different steps. Virtually all processes take place at the molecular level, focusing on molecules of phytochemicals and enzymes, and their metabolic actions. ${ }^{5}$ Based on experimental studies, hepatotoxic ingredients of herbal TCMs or their mostly reactive metabolites commonly cause depletion of hepatic glutathione stores and a reduction of cytoskeleton-associated protein thiols; this leads to formation of plasma membrane blebs, causes apoptosis of liver cells, and induces liver injury, ${ }^{56,64}$ possibly through an immuno-allergic reaction. ${ }^{5}$ However, such pathogenetic mechanisms of intrinsic liver injury are hardly transferable to idiosyncratic HILI, as has often been done erroneously.

\section{DILI}

As with HILI caused by TCMs, the majority of liver injury by Western drugs is based on idiosyncrasy without the option of pathogenetic evaluation in experimental animals or in patients. ${ }^{38,65}$ In line with the low incidence and prevalence rates of idiosyncratic DILI in the general population, some genetic variations in host receptors, variable immune responses, and various metabolic pathways are under discussion for the pathogenetic sequelae of idiosyncratic DILI. ${ }^{65,66}$ Among the most frequent synthetic drugs causing idiosyncratic DILI are antimicrobials, such as amoxicillin/clavulanate, nitrofurantoin, sulfamethoxazole/trimethoprim, ciprofloxacin, and isoniazid. 1,4,9,15-21,27-30,67,68 Similarly, agents for molecular target therapy, like tyrosine kinase inhibitors and tumor necrosis factor- $\alpha$ inhibitors, can also induce idiosyncratic drug reactions. ${ }^{69}$ Although little is known about the mechanisms and pathways underlying how drugs initiate and maintain idiosyncratic DILI, ${ }^{15}$ risk factors of disease initiation and perpetuation are known. ${ }^{38}$ Among these potential risk factors are age, sex, genetic factors, pubertal development, hormonal changes, nutritional status, pregnancy, and co-medication; also, underlying disease conditions and the gut microbiome could affect DILI occurrence and progression. ${ }^{38}$ 
Instead, intrinsic DILI can be reproduced in animal studies and is, therefore, well characterized with respect to pathogenetic mechanisms of injury that are transferrable to human intrinsic DILI, with liver injury by acetaminophen as a good example. ${ }^{65}$ Intrinsic liver injury by acetaminophen is commonly dose-dependent, and its animal models facilitate our understanding of the molecular steps that are responsible for hepatocellular injury. ${ }^{70}$ The hepatic metabolism of acetaminophen leads to $\mathrm{N}$-acetyl-p-benzoquinone imine (NAPQI), which is detoxified by hepatic glutathione. ${ }^{69,71}$ Accumulation of NAPQI initially reduces hepatic glutathione, and upon its exhaustion, NAPQI not bound to glutathione causes centrilobular hepatic necrosis. ${ }^{72}$ Thus, experimental acetaminophen overdose is a good example for human intrinsic DILI.

\section{Study cohorts of HILI by TCMs as compared to DILI}

\section{Background}

Chemicals of different structures are the culprits of both liver injury entities, HILI and DILI, with botanical chemicals of TCM herbs being responsible for HILI by TCMs as opposed to synthetic chemicals of drugs accounting for DILI. Prompted by a recently published study in China, which provided the homogenous ethnicity of the cohorts and compared, for the first time, HILI by TCM herbs with DILI by synthetic drugs within a single study protocol, ${ }^{1}$ a further discussion of these two unique injury types described in this comparative study of two cohorts is warranted.

\section{Case definition and liver injury classification}

The comparative analysis comprised two study cohorts, one consisting of 563 patients with suspected HILI by TCMs and one of 870 patients with suspected DILI by Western drugs. ${ }^{1}$ The diagnostic criteria of DILI and HILI as outlined for RUCAM, which were updated in $2016,{ }^{16}$ were used to select patients for inclusion in the comparative study. ${ }^{1}$ The inclusion criteria included elevated ALT $>5 \times$ ULN or alkaline phosphatase $(A L P)>2 \times$ ULN. It was mandatory for diagnostic exclusion of hepatotropic virus infections (by specific antibody test or other parameters), as well as of hepatitis E virus (HEV) infections (by anti-HEV IgM and IgG testing), non-hepatotropic virus infections, autoimmune liver disease, alcoholic liver disease, and metabolic disorders. Liver injury pattern was classified in all cases of the two cohorts, ${ }^{1}$ again in line with criteria of RUCAM. ${ }^{16}$ Thereby, liver injury was designed as hepatocellular, cholestatic, or mixed in the comparative study. ${ }^{1}$ The distribution of liver injury classification in the Chinese study comparing the cohort of HILI by TCMs with the DILI cohort is shown in Fig. 1.

\section{Clinical features of HILI by TCMs and DILI by Western drugs}

Clinical manifestation is similar for liver injury by drugs as compared to herbs. ${ }^{1,32,34,73}$ For instance, the latency period of DILI ranges from a few days to several months. ${ }^{73}$ The first signs of DILI usually emerge within the initial 6 months of treatment with a new drug, whereas liver injury associated with few other specific causative agents can occur after a longer latency period. ${ }^{35}$ For a newly used Chinese herbal medication, the median time to develop liver injury was 3 months. ${ }^{33}$

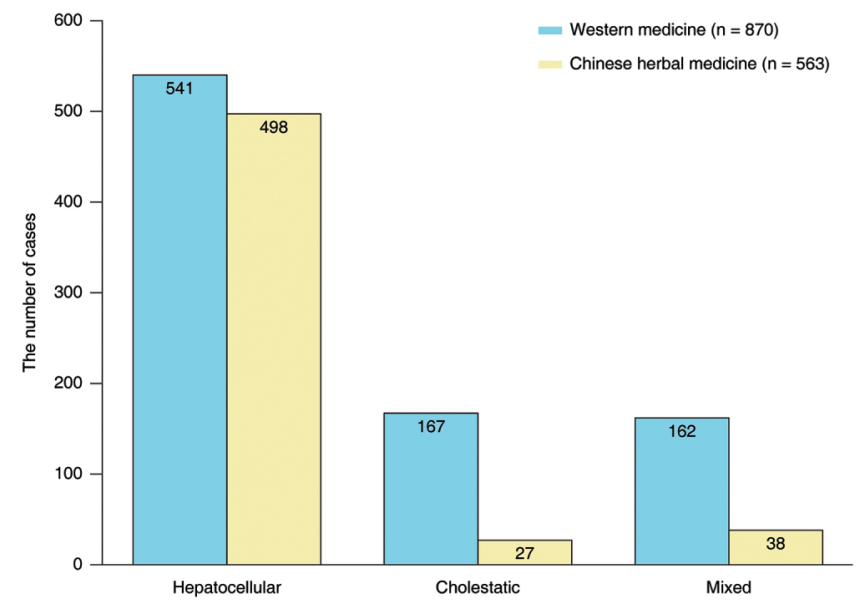

Fig. 1. Classification of liver injury caused by Western medicine compared to Chinese herbal medicine, ${ }^{1}$ as determined by the ratio $(R)$ value and calculated as: $[($ ALT/ULN $) /($ ALP/ULN $)] .{ }^{16}$ Accordingly, the pattern of liver injury is hepatocellular $(R \geq 5)$, cholestatic $(R \leq 2)$, or mixed $(2<R<5){ }^{16}$ Abbreviations: ALP, alkaline phosphatase; ALT, alanine aminotransferase; ULN, upper limit of normal.

In general, most patients with suspected HILI or DILI are asymptomatic or have mild LT abnormalities with marginally elevated ALT, aspartate aminotransferase (AST), or ALP. ${ }^{35}$ Only a small proportion of HILI or DILI patients have clinical signs of fatigue, lack of appetite, nausea, epigastric pain and abdominal discomfort. ${ }^{34,74}$ Jaundice, pruritus and discolored stool often occur in patients suffering from cholestatic liver injury by use of synthetic drugs or herbal TCMs. ${ }^{32,34,73}$ Patients with liver injury rarely experience extrahepatic hypersensitive symptoms like fever, rash, and blood eosinophilia. ${ }^{32,34}$ Severe DILI or HILI can result in acute liver failure (ALF), whereby patients may need a liver transplant or may even die. ${ }^{1,75}$

Progress has been made in defining the features of the two cohorts consisting of HILI by TCMs and DILI by Western drugs, as detailed in a recent study. ${ }^{1}$ In this retrospective analysis, causative agents, either TCMs or Western drugs, are almost always administered orally. ${ }^{1}$ This study was achieved through a comparative evaluation of liver injury cases with established causality using RUCAM $^{1}$ the preferred CAM for injury cases. ${ }^{16}$ This study ultimately presented cohort characteristics, including epidemiology details of incidence and prevalence, constituent ratio and demographics of the DILI and HILI cohorts, in addition to pathogenetic details, clinical characteristics, risk factors, liver histopathology, outcome and prognosis. ${ }^{1}$ Parts of the published results are presented in Table 4.

\section{Impact of risk factors}

Possible risk factors of HILI focus on the individual who consumes herbal TCM and on the herbal TCM product that was itself used. There is ample evidence that herbal TCM product quality is variable and disputed. ${ }^{1,32}$ First, herbal TCM mixtures may contain toxic herbs, which initiate liver injury after ingestion. ${ }^{32}$ Second, herbal products could be contaminated with hazardous materials, like heavy metals, mycotoxins or pesticides, ${ }^{12,60,76,77}$ substituted with alternative plant species and fillers without elucidative labels, ${ }^{78}$ or implicated 
Jing J. et al: Traditional Chinese medicine for liver injury

Table 4. Clinical characteristics of patients with DILI by Western medicine as compared to patients with HILI by Chinese herbal medicine

\begin{tabular}{llll}
\hline Characteristic & Western Medicine, $n=870$ & Chinese Herbal Medicine, $n=563$ & $p$ \\
\hline Age in years, mean \pm SD & $43 \pm 15$ & $43 \pm 14$ & 0.826 \\
Male/female, $n$ & $426 / 444$ & $163 / 400$ & $<0.001$ \\
Alcohol use ${ }^{\dagger}, n$ & 183 & 68 & $<0.001$ \\
Allergy history, $n$ & 148 & 90 & 0.443 \\
Prevalence ${ }^{\ddagger}, \%$ & 8.98 & 5.81 & 0.419 \\
Liver tests with peak values, mean \pm SD & & $983 \pm 652$ & $<0.001$ \\
ALT in U/L & $952 \pm 810$ & $196 \pm 125$ & 0.431 \\
ALP in U/L & $313 \pm 214$ & $11.2 \pm 9.2$ & $<0.001$ \\
TB in mg/dL & $10.8 \pm 10.8$ & $1.23 \pm 0.52$ & 0.046 \\
INR & $1.36 \pm 0.65$ & 8.9 & $<0.001$ \\
Positive unintentional re-challenge, \% & 6.1 & 88.5 & $<0.001$ \\
Liver injury pattern, \% & & 4.8 & $<0.001$ \\
Hepatocellular & 62.2 & 6.7 & \\
Cholestatic & 19.2 & 18.6 & \\
Mixed & & & \\
\hline
\end{tabular}

Data were adapted from a previous report. ${ }^{1}$

${ }^{\dagger}$ The drinking history of these patients (alcohol intake of $>2$ drinks per day in women and $>3$ drinks per day in men) had been called for the exclusion of drinking within the latest month before liver injury.

${ }^{\ddagger}$ Prevalence data of patients with DILI caused by Western medicine and HILI caused by Chinese herbal medicine are calculated from the 96857 hospitalized patients. ${ }^{1}$ Abbreviations: ALT, alanine aminotransferase; ALP, alkaline phosphatase; DILI, drug-induced liver injury; INR, international normalized ratio; TB, total bilirubin.

in unreasonable processing of the herbal drug. ${ }^{79}$ However, such quality aspects are less carefully investigated, and uncertainty exists as to what extent product quality problems may trigger liver injury and represent a major risk factor.

On the side of the consumer, unreasonable TCM treatment is proposed as a possible cause of HILI, representing a potential risk factor. ${ }^{80}$ Immunological aspects, not further specified individual differences, or underlying diseases are also discussed as being risky. ${ }^{24,38}$ In addition, metabolic interactions of chemicals derived from Chinese herbs with chemicals of conventional drugs may occur and provoke liver injury, especially in multi-medicated patients. ${ }^{1,32}$ In view of the product heterogeneity of herbal TCMs and the variable individual susceptibility of consumers, it is hard to conclusively identify valid risk factors of liver injury in connection with the use of most herbal TCM products.

As opposed to the TCM herbs, risk factors of liver injury are much better investigated for conventional drugs. ${ }^{34,73}$ Drugs are well defined by their chemical ingredients and quality requirements, as requested by surveillance programs of regulatory agencies. For assessing possible risk factors in DILI, the focus is, thus, more on the susceptibility of the patients than on issues of drug product quality. The susceptibility of idiosyncratic DILI refers mainly to genetic risk factors and less to non-genetic risk factors. ${ }^{15,34}$ In previous clinical studies involving patients with liver injury by conventional drugs, the genetic impact was favored as a risk factor, focusing on human leucocyte antigen alleles and genetic polymorphisms of drug metabolizing enzymes. ${ }^{39,66}$ Although genetic factors predisposing individuals at risk are important, the physicochemical and toxicological properties of drugs, host and environmental factors, and their metabolic interactions are other (but non-genetic) potential risk factors to be considered. ${ }^{34,38}$ Among these non-genetic risk factors of idiosyncratic DILI are lipophilicity, extensive drug metabolism, and high daily doses of the used drug as molecular risk factors of liver injury caused by drugs. $5,38,65$

Additional risk factors of DILI have previously been identified and merit brief comments. In line with data analyzed and validated by RUCAM, amounts of alcohol consumed are specifically provided for women (2 drinks/day) and men (3 drinks/day), calculating on average $10 \mathrm{~g}$ ethanol for each drink. $^{81,82}$ Other studies confirmed alcohol use as a risk factor of DILI. For instance, according to a British population-based case-control study of DILI, alcohol use was a potential confounder of DILI among 128 assessable cases, with an odds ratio of up to 2.0, achieved if $>10$ units were consumed within a week, where 1 unit corresponded to one glass of wine. ${ }^{17}$ In line with this study, other reports considered alcohol use as a risk factor of DILI. $5,14,16,83,84$ Under discussion is the increased risk of alcohol use for DILI with some drugs, such as acetaminophen, ${ }^{71}$ halothane, ${ }^{85,86}$ isoflurane, ${ }^{87}$ isoniazid, ${ }^{67,68}$ and various anti-tuberculosis drugs, ${ }^{88}$ including rifampicin and isoniazid in combination ${ }^{67}$ and the drugs for treatment of multidrug-resistant tuberculosis, ${ }^{88}$ methotrexate, and other drugs. ${ }^{89}$

In a study on patients with pulmonary tuberculosis under treatment with various anti-tuberculosis drugs, the multivariate analysis revealed prior alcohol consumption as a significant risk factor of recurrent DILI with an odds ratio of $2.2{ }^{89}$ Consequently, ample evidence exists that chronic alcoholism is a risk factor for DILI due to various drugs. ${ }^{16,17}$ It is subsequently justified that alcohol use as a risk factor of DILI is included as an item of RUCAM, providing one point in the original RUCAM ${ }^{17}$ as well as in the RUCAM update of $2016 .{ }^{16}$ Age $\geq 55$ years is also included as a scored risk factor, in line with validated data analyzed in several cases. ${ }^{16,81,82}$ Additionally, as a condition lowering the threshold of cholestasis 
Jing J. et al: Traditional Chinese medicine for liver injury

due to the high estrogen concentrations, pregnancy is described as a risk factor specifically for cholestatic/mixed liver injury. ${ }^{16,81}$

\section{Histopathology issue}

Liver biopsy is not a mandatory or facultative key item examination of RUCAM, ${ }^{16}$ because histopathological changes in DILI and HILI lack specific characteristics. ${ }^{90}$ Pathological findings in combination with corresponding patients' clinical presentations are rarely beneficial for the patient, since the exclusion of other liver diseases in suspected HILI and DILI cases is more important and must be achieved by non-invasive methods (i.e. laboratory and serology analyses) rather than by invasive methods (i.e. liver biopsy), although risk of procedural-associated complications is low. ${ }^{34}$

Generally, DILI and HILI can induce various target lesions at the cellular level, including hepatocyte, biliary epithelial cell, and vascular endothelial cell in hepatic sinus and intrahepatic veins. ${ }^{67,73}$ Liver pathology changes in suspected HILI cases are commonly viewed as unspecific and not contributory to firmly establish the HILI diagnosis. There are some histology findings, such as confluent liver cell necroses, fibrous septum formation and periportal lymphoplasmacytic infiltrations, which are more likely to be observed in HILI than in DILI cases; but, such differences cannot be used as diagnostic differentiating criteria in liver injury patients, who used herbs or drugs. ${ }^{67,91}$ Nevertheless, some specific histological characteristics, such as HSOS, are present in suspected HILI caused by a few Chinese herbal medicines (CHMs), such as Tusanqi, with PAs as ingredients. ${ }^{64}$

\section{Outcome and prognosis}

Patients experiencing acute liver injury following use of herbal TCMs or drugs commonly have a good outcome and longterm prognosis. ${ }^{12,29,34,84,92} \mathrm{ALF}$ and requirement of liver transplantation are serious but rare complications. ${ }^{4,34,93}$ The overall outcome is better in patients with liver injury caused by herbal TCMs or chemical drugs than in those with chronic liver diseases. ${ }^{73}$ Details of outcome and prognosis are summarized in Table 5, but additional aspects are important, such as age, sex, liver biochemistries and a clinical pattern of liver injury, as outlined in various publications. $1,37,94-96$

In a retrospective DILI analysis from Korea 30 days after case enrollment, $13.1 \%$ of the patients had a poor prognosis, with model of end-stage liver disease score and hemoglobin concentration as independent predictors of prognosis for these patients with DILI. ${ }^{94}$ In another retrospective study carried out from 2009 to 2013 in Thailand, an increased hazard ratio (HR) signified major risk factors of mortality that were found in those patients with suspected DILI and who suffered from liver cirrhosis ( $\mathrm{HR}=2.72,95 \%$ confidence interval (CI): 2.33-3.19), infections by the human immunodeficiency virus ( $\mathrm{HR}=2.11,95 \% \mathrm{CI}: 1.88-2.36)$ or chronic renal disease $(\mathrm{HR}=1.59,95 \% \mathrm{CI}: 1.33-1.90)$, or who were aged $\geq 60$ years $(\mathrm{HR}=2.16,95 \% \mathrm{CI}: 1.96-2.38) .{ }^{95}$ Similarly, $8 \%$ of enrolled patients with DILI from a study in the United States died and $2.1 \%$ underwent liver transplantation. ${ }^{37}$ Other data of prognosis were obtained from the Spanish DILI registry for DILI patients with hepatocellular injury and jaundice, whose ALT values were $>3 \times$ ULN with total bilirubin values $>2 \times$ ULN; ten percent of these patients developed ALF. $^{96}$

In a Chinese cohort of 1985 patients with DILI or HILI, 155 patients $(7.8 \%)$ were diagnosed with ALF, 103 patients (5.2\%) died, and 19 patients $(1.0 \%)$ received a liver transplant; with respect to HILI, among 66 patients with liver injury caused by $P$. multiflorum and its compound preparation, $4(6.1 \%)$ presented with ALF and $2(3.0 \%)$ died. ${ }^{1}$ These data were corroborated in another DILI/HILI study of patients with ALF or acute liver injury, who were treated in 32 liver centers in the United States. ${ }^{97}$ The comparison of DILI with HILI, which included complementary medicines and dietary supplements, showed that patients of the HILI group, who progressed to ALF, had a higher rate of transplantation, with a lower transplant-free survival among those. ${ }^{97}$ The comparative data of clinical outcome and prognosis among patients with DILI and HILI caused by herbal TCM medicines are summarized in Table 5.

Table 5. Comparison of clinical outcomes and prognosis between DILI patients and HILI patients

\begin{tabular}{|c|c|c|c|c|c|c|c|c|c|c|c|c|}
\hline \multirow{2}{*}{$\begin{array}{l}\text { First } \\
\text { author Ref }\end{array}$} & \multirow[b]{2}{*}{ Period } & \multirow[b]{2}{*}{ Country } & \multirow{2}{*}{$\begin{array}{l}\text { DILI } \\
\text { cases, } \\
n\end{array}$} & \multirow{2}{*}{$\begin{array}{l}\text { HILI } \\
\text { cases*, }_{n} \text {, }\end{array}$} & \multicolumn{2}{|c|}{ Recovery } & \multicolumn{2}{|l|}{ ALF } & \multicolumn{2}{|c|}{ Chronic } & \multicolumn{2}{|c|}{$\begin{array}{l}\text { Death/liver } \\
\text { transplantation }\end{array}$} \\
\hline & & & & & DILI & HILI* & DILI & HILI* & DILI & HILI* & DILI & HILI* $^{*}$ \\
\hline Takikawa 27 & $\begin{array}{l}1997- \\
2006\end{array}$ & Japan & 1676 & 64 & 1613 & 64 & I & I & I & I & $63^{\dagger}$ & 0 \\
\hline$W a i^{28}$ & $\begin{array}{l}2004- \\
2006\end{array}$ & Singapore & 22 & 13 & 20 & 13 & / & / & / & / & $2^{\dagger}$ & 0 \\
\hline Fontana ${ }^{92}$ & $\begin{array}{l}2004- \\
2011\end{array}$ & USA & 660 & $108^{\#}$ & 485 & / & / & / & 113 & $18^{\#}$ & $17 / 30$ & $1 / 8^{\#}$ \\
\hline $\mathrm{Lee}^{29}$ & $\begin{array}{l}2003- \\
2013\end{array}$ & Korea & 65 & 28 & 65 & 28 & / & / & / & / & 0 & 0 \\
\hline $\mathrm{Zhu}^{1}$ & $\begin{array}{l}2009- \\
2014\end{array}$ & China & 1985 & 563 & 1654 & 463 & 155 & 43 & 256 & 70 & $64 / 12$ & $27 / 2$ \\
\hline
\end{tabular}

\footnotetext{
*The group of HILI was defined as liver injury caused by CHMs or HDS.

${ }^{\dagger}$ Reported data referred to all cases including deaths or liver transplantations.

\# Cases of HILI were all caused by HDSs.

Abbreviations: ALF, acute liver failure; CHMs, Chinese herbal medicines; DILI, drug-induced liver injury; HDS, herbs and dietary supplements; HILI, herb-induced liver injury.
} 
Jing J. et al: Traditional Chinese medicine for liver injury

Table 6. Comparison of the RUCAM-based causality gradings of DILI patients with HILI patients

\begin{tabular}{lll}
\hline RUCAM-based causality gradings & Western medicine, $\boldsymbol{n}=\mathbf{8 7 0}$ & Chinese herbal medicine, $\boldsymbol{n}=\mathbf{5 6 3}$ \\
\hline Highly probable, \% & 60.3 & 16.6 \\
Probable, \% & 38.4 & 75.6 \\
Possible, \% & 1.3 & 7.6 \\
Unlikely, \% & 0 & 0.2 \\
Excluded, \% & 0 & 0 \\
\hline
\end{tabular}

Data of the HILI patients were derived from a previous study. ${ }^{1}$ RUCAM-based causality grading was achieved according to previous reports. ${ }^{16,81,82}$ Abbreviations: DILI, drug-induced liver injury; HILI, herb-induced liver injury; RUCAM, Roussel Uclaf Causality Assessment Method.

For few patients, a chronic course of DILI or HILI due to TCM was assumed, but evidence is limited. This commonly raises the question of whether a preexisting liver disease was initially overlooked due to incomplete data. ${ }^{34}$ It has been suggested that approximately $15-20 \%$ of patients experiencing acute DILI developed chronic DILI, ${ }^{34,37}$ with partial improvement in the further course ranging from 3 months to 3 years. ${ }^{18}$ In clinical practice, a minority will likely have a poor prognosis due to vanishing bile duct and cholestatic cirrhosis, but many other causes for these conditions are to be discussed. Among 863 patients with DILI and HILI hospitalized in a specialized clinic of Beijing, the diagnosis of chronic DILI was suggested by liver biopsy in 256 patients (12.9\%), but applied criteria of chronicity remained vague; out of 66 cases with liver injury in connection with $P$. multiflorum use and its compound preparation, 11 patients (16.7\%) may have developed HILI, assumed as such from the chronic type. ${ }^{1}$ Again, it remains a case-by-case decision whether acute liver injury can become a chronic disease.

\section{Causative agents}

A prospective cohort study of 96 DILI patients in Iceland from 2010 through 2011 showed that 38 patients were diagnosed with DILI caused by antibiotics; among these was amoxicillin/ clavulanate, the most used drug (in 21 out of 96 patients, $22 \%) .{ }^{20}$ Similarly, among 899 DILI cases between 2004 and 2014 , the antibiotic and antimicrobial drugs ( $n=408 ; 51 \%)$ like azithromycin, nitrofurantoin and minocycline represented the implicated agents in higher proportions of patients with pre-existing liver diseases $(n=89 ; 9.8 \%)$ and DILI cases with long latency $(n=12 ; 1.3 \%){ }^{30}$ In another analysis of 1985 cases in China from 2009 to 2014, the most commonly implicated antibiotics were azithromycin, amoxicillin, levofloxacin, norfloxacin and roxithromycin, ${ }^{1}$ similar to Western countries. 20,30

Among 839 patients with liver injury due to WMs and HDS, 130 patients had HDS-induced liver injury including 45 patients (35\%) who had used bodybuilding HDS and 85 patients $(65 \%)$ who had been on non-bodybuilding HDS. ${ }^{31}$ A systematic review on HILI in Korea identified 21 herbal preparations with P. multiflorum (39.2\%) and Dictamnus dasycarpus $(37.1 \%)$ as the most common causative agents. $^{98}$ In a retrospective analysis of 427 cases with suspected liver injury caused by herbal TCMs in China between 1983 and 1998, He Shou Wu (as a single species of Chinese herb) and Zhuanggu Guanjie Wan (as a multispecies Chinese patent medicine) were the most common causative agents of liver injury. ${ }^{36}$ Clinical data of another specialized hospital collected from 2009 to 2014 identified P. multiflorum $(n=66)$,
Psoralea corylifolia $(n=39)$ and Corydalis yanhusuo $(n=36)$ as the three major Chinese herbs associated with liver injury. ${ }^{1}$

Unfortunately, robust comparative data on treatment duration and daily dosage of suspected drugs and herbs are not available from the large sample cohorts of DILI and HILI cases. However, compared with WM and referencing a Chinese report in Chinese language, there is the note that liver injury caused by TCM develops slowly with clinical symptoms appearing within 1 week to 1 month. ${ }^{55}$ In addition, daily doses of herbs used as herbal mixtures are difficult to assess due to the variability of the herbal products and the unknown amount of the respective phytochemicals.

\section{Treatment indication}

For WMs, treatment conditions are transparent and commonly accessible, conditions that rarely apply to treatments by herbs, including TCM herbs and dietary supplements. In the United States, indications for HDS use were among others for body-building (33\%), weight loss (26\%), immune support $(12 \%)$ and cough/cold (11\%). ${ }^{99}$ Indications for herbal TCMs were osteoarthropathy $(33.4 \%)$, nephropathy $(25.9 \%)$ and unspecified dermatosis $(20.3 \%){ }^{36}$

\section{Diagnostic strategy of causality assessment using RUCAM}

Causality assessment approaches in patients with liver injury may be difficult if several products were used concomitantly or if Chinese traditional patent medicines were used, which consist of multispecies herbs. ${ }^{99-101}$ For instance, a single HDS product was implicated in $60 \%$ of patients included in a case series of the liver injury, two or more in $23 \%$, and a combination of HDS with prescribed drugs in $16 \%$, which confounded the results that were not assessed for causality specifically by RUCAM. ${ }^{99}$ More importantly, RUCAM as the most commonly applied CAM worldwide ${ }^{16}$ was also used in the recent comparative cohort study of DILI and HILI by TCM. ${ }^{1}$ This identical approach of causality assessment qualified the results by ensuring valid and comparable data for both cohorts (Table 6). ${ }^{1,2,11,16,102-105}$

RUCAM-based causality gradings for individual products differed slightly between the cohort of HILI by TCMs and DILI. ${ }^{1}$ However, most impressing were the high RUCAMbased causality gradings, which were highly probable or probable for both cohort groups, which signifies good case data quality, as evidenced by the completeness of the RUCAM items to be scored. Among the 866 cases of liver injury due to a single agent, the final RUCAM gradings were highly probable in $37 \%$ of the cases, probable in $59 \%$, possible in $5 \%$, 
Jing J. et al: Traditional Chinese medicine for liver injury

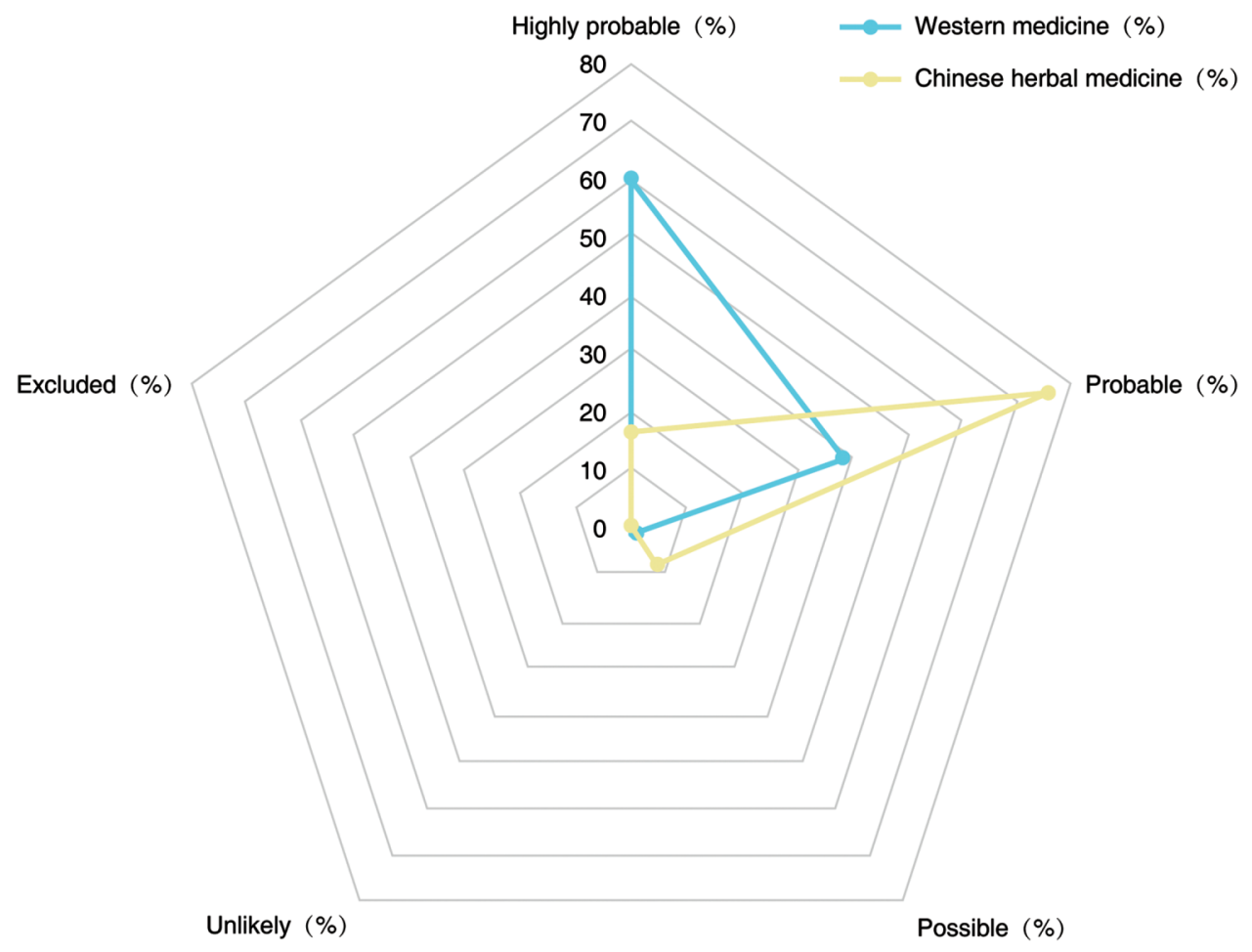

Fig. 2. Comparative distribution of the RUCAM gradings in patients with liver injury caused by Western medicine and Chinese herbal medicine. Data are derived from a previous study; ${ }^{1}$ details of RUCAM-based causality gradings were provided by the report of Danan and Teschke. ${ }^{16}$

Abbreviation: RUCAM, Roussel Uclaf Causality Assessment Method.

likely in $0.1 \%$, and excluded in none among 390 cases caused by WMs and 446 cases caused by CHMs. ${ }^{1}$ In detail, in the group with the highly probable causality grading, liver injury caused by CHMs predominated, whereas the probable causality level was found preferentially in the WMs group (Fig. 2). ${ }^{1}$

A large number of registries, regulatory agencies, and major associated groups of Europe and Asian countries applied RUCAM to assess causality in suspected cases of DILI and HILI; details have been reported in a previous publication. ${ }^{16}$ In addition, RUCAM is used worldwide and has been reported on in many case reports and case series of suspected DILI and HILI. ${ }^{16,41,106-112}$ RUCAM was originally published in $1993^{81,82}$ and updated in $2016 .{ }^{16}$ It is applicable in suspected DILI and HILI cases to be used for robust causality assessment. Representing a structured, standardized and hepatotoxicity-specific diagnostic algorithms, the RUCAM attributes individual scores to each key item. Summing up the individual scores will provide final quantitative causality gradings. ${ }^{16}$

Among the various core elements of RUCAM are: challenge characteristics as time period from beginning until cessation of drug or herb use in relation to disease onset or from the cessation of product use to the onset of the liver injury; dechallenge features with a course of LTs after cessation or continuation of the product's use; risk factors, including alcohol use, age and pregnancy; co-medication with other drugs or herbs; search for alternative causes, including HEV among others; available information on previously known hepatotoxicity; and, specific ALT criteria for response to unintentional re-challenge to be assessed retrospectively, as intentional prospective re-challenge for diagnostic purposes is obsolete and unethical due to the high risks associated with this test. ${ }^{16}$

Rare differential diagnoses should be excluded and are provided in a separate list of the updated RUCAM. ${ }^{16}$ Additional details of RUCAM can be found in the updated version that should now be used in future DILI and HILI cases. ${ }^{16}$ Apart from RUCAM, other CAMs have been used in suspected DILI and HILI cases but most of these, including approaches based on expert opinion, received critical comments. ${ }^{16}$

\section{Potential diagnostic biomarkers}

Biomarkers, in the form of blood tests as specific diagnostic tools, would be appreciated by clinicians, regulators and the pharmaceutical industry if, in addition to RUCAM, the causality of idiosyncratic DILI and HILI can be confirmed. ${ }^{5,113}$ However, for any diagnostic biomarkers including those considered to be used for idiosyncratic DILI and HILI, high specificities and sensitivities are required. Most importantly, potential new diagnostic biomarkers must be evaluated in idiosyncratic DILI and HILI patients with established RUCAMbased causality of highly probable or probable causality gradings. ${ }^{113}$

Diagnostic biomarkers are available for a few drugs and herbs, which cause intrinsic but not idiosyncratic DILI or HILI. ${ }^{5,113}$ For example, valid biomarkers of acetaminophen protein adducts in serum and urine are available in patients with intrinsic DILI or ALF caused by overdosed acetaminophen, also called $\mathrm{N}$-acetyl-para-aminophenol (APAP) or paracetamol. ${ }^{113}$ Serum microsomal epoxide hydrolase is another 
Jing J. et al: Traditional Chinese medicine for liver injury

diagnostic biomarker, to be used in Western countries for the diagnosis of intrinsic HILI caused by Germander, ${ }^{5,62,63}$ which is known in China as Shi Can. ${ }^{4}$ Serum pyrrole-protein adducts are other diagnostic biomarkers for HILI are due to the herbal TCM San Chi (Gynura segetum) with unsaturated PAs as ingredients and culprits causing HSOS. ${ }^{4,5}$ Many other biomarkers including microRNA-122 or keratin-18 are under consideration but still disputed due to limited test validation. ${ }^{5,113}$

Presently, no specific diagnostic biomarker is available that could assist RUCAM in clarifying and ascertaining the diagnosis of idiosyncratic HILI or DILI, which remain diagnoses of exclusion. However, many diagnostic serum biomarkers are key items of RUCAM items to exclude infections such as hepatitis A virus, hepatitis B virus, hepatitis $C$ virus, HEV, cytomegalovirus, Epstein-Barr virus, herpes simplex virus and varicella zoster virus, using specific PCR analysis and specific serology parameters such as IgM or IgG antibodies. ${ }^{9}$ In addition, a wide range of diagnostic tools are available to exclude the broad spectrum of autoimmune liver diseases including autoimmune hepatitis. ${ }^{9}$ A careful diagnosis is essential, because alternative causes are often detected in case series of DILI ${ }^{84,114}$ and HILI ${ }^{115}$ and confound the diagnosis, with the consequence that suspected HILI and DILI are not HILI or DILI but something else.

\section{Conclusions}

Western drugs and herbal products, including TCMs, are commonly applied for therapeutic purposes with variable efficacy, but they may represent potential exogenous hazards in worldwide healthcare settings if liver injury emerges. There has been uncertainty as to whether DILI has different characteristics as compared to HILI caused by TCM. Despite some concordance, new analyses of liver injury cases with established RUCAM-based causality revealed major differences of HILI caused by TCMs as compared to DILI regarding the following features: in a general liver injury setting, HILI cases are less frequently observed as compared to DILI, have a smaller proportion of females and less rechallenge events, and present a higher rate of hepatocellular injury features. Since all results were obtained from Chinese residents who had access to and used Western drugs and/ or TCM herbs, the ethnic homogeneity of the assessed population suggests that the observed differences are well founded within one ethnic group.

\section{Acknowledgments}

Supported by the Specialized Research Fund of National Traditional Chinese Medicine Clinical Research and Base Construction Project (No. JDZX2015188): The study of the pathogenesis of herb-induced liver injury.

\section{Conflict of interest}

The authors have no conflict of interests related to this publication.

\section{Author contributions}

Contributed equally to this manuscript and approved the final version to be published (JJ, RT).

\section{References}

[1] Zhu Y, Niu M, Chen J, Zou ZS, Ma ZJ, Liu SH, et al. Hepatobiliary and pancreatic: Comparison between Chinese herbal medicine and Western medicine-induced liver injury of 1985 patients. J Gastroenterol Hepatol 2016;31:1476-1482. doi: 10.1111/jgh.13323.

[2] Jung KA, Min HJ, Yoo SS, Kim HJ, Choi SN, Ha CY, et al. Drug-induced liver injury: twenty five cases of acute hepatitis following ingestion of polygonum multiflorum thunb. Gut Liver 2011;5:493-499. doi: 10.5009/gnl.2011.5.4. 493.

[3] Cortez E, Boulger C, Bernard A. Ban Tu Wan hepatotoxicity. BM] Case Rep 2012;2012. doi: 10.1136/bcr-2012-006438.

[4] Teschke R, Zhang L. Chinese herbs and their molecules: Clinical and pathophysiological implications for the liver. J Mol Pathophysiol 2015;4:85-93. doi: $10.5455 / j m p .20150710032817$.

[5] Teschke R, Larrey D, Melchart D, Danan G. Traditional chinese medicine (TCM) and herbal hepatotoxicity: RUCAM and the role of novel diagnostic biomarkers such as microRNAs. Medicines (Basel) 2016;3:18. doi: 10. 3390/medicines3030018.

[6] Teschke R, Eickhoff A. Herbal hepatotoxicity in traditional and modern medicine: actual key issues and new encouraging steps. Front Pharmacol 2015; 6:72. doi: 10.3389/fphar.2015.00072.

[7] Melchart D, Linde K, Weidenhammer W, Hager S, Shaw D, Bauer R. Liver enzyme elevations in patients treated with traditional Chinese medicine. JAMA 1999;282:28-29. doi: 10.1001/jama.282.1.28.

[8] Melchart D, Hager S, Dai J, Weidenhammer W. Quality control and complication screening programme of Chinese medicinal drugs at the first German hospital of Traditional Chinese Medicine - a retrospective analysis. Forsch Komplementmed 2016;23 Suppl 2:21-28. doi: 10.1159/000444983.

[9] Frenzel C, Teschke R. Herbal hepatotoxicity: clinical characteristics and listing compilation. Int J Mol Sci 2016;17:588. doi: 10.3390/ijms17050588.

[10] Lin G, Wang JY, Li N, Li M, Gao H, Ji Y, et al. Hepatic sinusoidal obstruction syndrome associated with consumption of Gynura segetum. J Hepatol 2011;54:666-673. doi: 10.1016/j.jhep.2010.07.031.

[11] Gao H, Li N, Wang JY, Zhang SC, Lin G. Definitive diagnosis of hepatic sinusoidal obstruction syndrome induced by pyrrolizidine alkaloids. J Dig Dis 2012;13:33-39. doi: 10.1111/j.1751-2980.2011.00552.x.

[12] Teschke R. Traditional Chinese medicine induced liver injury. J Clin Transl Hepatol 2014;2:80-94. doi: 10.14218/JCTH.2014.00003.

[13] Teschke R, Andrade RJ. Drug-induced liver injury: expanding our knowledge by enlarging population analysis with prospective and scoring causality assessment. Gastroenterology 2015;148:1271-1273. doi: 10.1053/j. gastro.2015.04.027.

[14] Teschke R, Andrade RJ. Drug, herb, and dietary supplement hepatotoxicity. Int J Mol Sci 2016;17:1488. doi: 10.3390/ijms17091488.

[15] Sarges $P$, Steinberg JM, Lewis JH. Drug-induced liver injury: highlights from a review of the 2015 literature. Drug Saf 2016;39:801-821. doi: 10.1007/ s40264-016-0427-8.

[16] Danan G, Teschke R. RUCAM in drug and herb induced liver injury: the update. Int J Mol Sci 2015;17:14. doi: 10.3390/ijms17010014.

[17] de Abajo FJ, Montero D, Madurga M, García Rodríguez LA. Acute and clinically relevant drug-induced liver injury: a population based case-control study. Br J Clin Pharmacol 2004;58:71-80. doi: 10.1111/j.1365-2125. 2004.02133.x.

[18] Andrade RJ, Lucena MI, Fernández MC, Pelaez G, Pachkoria K, García-Ruiz $E$, et al. Drug-induced liver injury: an analysis of 461 incidences submitted to the Spanish registry over a 10 -year period. Gastroenterology $2005 ; 129$ : 512-521. doi: 10.1016/j.gastro.2005.05.006

[19] Sgro C, Clinard F, Ouazir K, Chanay H, Allard C, Guilleminet C, et al. Incidence of drug-induced hepatic injuries: a French population-based study. Hepatology 2002;36:451-455. doi: 10.1053/jhep.2002.34857.

[20] Björnsson ES, Bergmann OM, Björnsson HK, Kvaran RB, Olafsson S. Incidence, presentation, and outcomes in patients with drug-induced liver injury in the general population of Iceland. Gastroenterology 2013;144: 1419-1425.e3. doi: 10.1053/j.gastro.2013.02.006.

[21] Woo HJ, Kim HY, Choi ES, Cho YH, Kim Y, Lee JH, et al. Drug-induced liver injury: A 2-year retrospective study of 1169 hospitalized patients in a single medical center. Phytomedicine 2015;22:1201-1205. doi: 10.1016/j. phymed.2015.10.002.

[22] Lucena MI, Andrade RJ, Kaplowitz N, García-Cortes M, Fernández MC, Romero-Gomez $\mathrm{M}$, et al. Phenotypic characterization of idiosyncratic drug-induced liver injury: the influence of age and sex. Hepatology 2009; 49:2001-2009. doi: 10.1002/hep.22895.

[23] Assis DN, Navarro VJ. Human drug hepatotoxicity: a contemporary clinical perspective. Expert Opin Drug Metab Toxicol 2009;5:463-473. doi: 10. $1517 / 17425250902927386$.

[24] Navarro VJ, Lucena MI. Hepatotoxicity induced by herbal and dietary supplements. Semin Liver Dis 2014;34:172-193. doi: 10.1055/s-00341375958. 
[25] Robles-Diaz M, Garcia-Cortes M, Medina-Caliz I, Gonzalez-Jimenez A Gonzalez-Grande R, Navarro JM, et al. The value of serum aspartate aminotransferase and gamma-glutamyl transpetidase as biomarkers in hepatotoxicity. Liver Int 2015;35:2474-2482. doi: 10.1111/liv.12834.

[26] Jüngst C, Gräber S, Klahn D, Wedemeyer H, Lammert F. Prevalence and risk factors of drug induced liver disease: a survey based study in pharmacies. Z Gastroenterol 2016;54:131-138. doi: 10.1055/s-0041-104024.

[27] Takikawa H, Murata Y, Horiike N, Fukui H, Onji M. Drug-induced liver injury in Japan: An analysis of 1676 cases between 1997 and 2006. Hepatol Res 2009;39:427-431. doi: 10.1111/j.1872-034X.2008.00486.x.

[28] Wai CT, Tan BH, Chan CL, Sutedja DS, Lee YM, Khor C, et al. Drug-induced liver injury at an Asian center: a prospective study. Liver Int 2007;27:465474. doi: 10.1111/j.1478-3231.2007.01461.x.

[29] Lee BM, Lee WC, Jang JY, Ahn P, Kim JN, Jeong SW, et al. Clinical features of drug-induced liver injury according to etiology. J Korean Med Sci 2015;30: 1815-1820. doi: 10.3346/jkms.2015.30.12.1815.

[30] Chalasani N, Bonkovsky HL, Fontana R, Lee W, Stolz A, Talwalkar J, et al. Features and outcomes of 899 patients with drug-induced liver injury: the DILIN prospective study. Gastroenterology 2015;148:1340-1352.e7. doi: 10.1053/j.gastro.2015.03.006.

[31] Navarro VJ, Barnhart H, Bonkovsky HL, Davern T, Fontana RJ, Grant L, et al. Liver injury from herbals and dietary supplements in the U.S. Drug-Induced Liver Injury Network. Hepatology 2014;60:1399-1408. doi: 10.1002/hep. 27317.

[32] Xiao XH, Li XH, Zhu Y, Wang ZB, Li L, Zhang T, et al. Guideline for diagnosis and treatment of herb-induced liver injury. J Clin Hepatol 2016;32:835843.

[33] Wu X, You H, Jia J. Clinical features of drug induced liver injury: A review of Chinese literatures 2003-2007. Chinese Hepatology 2008;13:463-466.

[34] Chalasani NP, Hayashi PH, Bonkovsky HL, Navarro VJ, Lee WM, Fontana RJ, et al. ACG Clinical Guideline: the diagnosis and management of idiosyncratic drug-induced liver injury. Am J Gastroenterol 2014;109:950-966. doi: 10.1038/ajg.2014.131

[35] Amacher DE. Female gender as a susceptibility factor for drug-induced liver injury. Hum Exp Toxicol 2014;33:928-939. doi: 10.1177/0960327113512860.

[36] Chen Y, Cai H. Investigation of liver damage associated with traditional Chinese medicines. Adverse Drug Reactions Journal 1999;1:27-32.

[37] Chalasani N, Fontana RJ, Bonkovsky HL, Watkins PB, Davern T, Serrano J, et al. Causes, clinical features, and outcomes from a prospective study of drug-induced liver injury in the United States. Gastroenterology 2008; 135:1924-1934.e4. doi: 10.1053/j.gastro.2008.09.011.

[38] Chen M, Suzuki A, Borlak J, Andrade RJ, Lucena MI. Drug-induced liver injury: Interactions between drug properties and host factors. J Hepatol 2015;63:503-514. doi: 10.1016/j.jhep.2015.04.016.

[39] Fontana RJ. Pathogenesis of idiosyncratic drug-induced liver injury and clinical perspectives. Gastroenterology 2014;146:914-928. doi: 10.1053/j. gastro.2013.12.032.

[40] Lin L, Ni B, Lin H, Zhang M, Li X, Yin X, et al. Traditional usages, botany, phytochemistry, pharmacology and toxicology of Polygonum multiflorum Thunb.: a review. J Ethnopharmacol 2015;159:158-183. doi: 10.1016/j. jep.2014.11.009.

[41] Wang J, Ma Z, Niu M, Zhu Y, Liang Q, Zhao Y, et al. Evidence chain-based causality identification in herb-induced liver injury: exemplification of a well-known liver-restorative herb Polygonum multiflorum. Front Med 2015;9:457-467. doi: 10.1007/s11684-015-0417-8.

[42] Lao A, Fujimoto $Y$, Tatsuno T. Constituents of Artemisia rubripes Nakai. Yakugaku Zasshi 1983;103:696-699. doi: 10.1248/yakushi1947.103.6_ 696.

[43] Judzentiene A, Budiene J, Butkiene R, Kupcinskiene E, Laffont-Schwob I, Masotti V. Caryophyllene oxide-rich essential oils of Lithuanian Artemisia campestris ssp. campestris and their toxicity. Nat Prod Commun 2010;5: 1981-1984.

[44] Wedin GP, Neal JS, Everson GW, Krenzelok EP. Castor bean poisoning. Am J Emerg Med 1986;4:259-261. doi: 10.1016/0735-6757(86)90080-X.

[45] MacLeod JK, Moeller PD, Franke FP. Two toxic kaurene glycosides from the burrs of Xanthium pungens. J Nat Prod 1990;53:451-455. doi: 10.1021/ np50068a025.

[46] Li CC, Chen Z. Observation on Hydrangeas role in fighting malaria and its preliminary pharmacological. Fu Jian Yi Xue Yuan Xue Bao 1959:1:93-97.

[47] Ikeda T, Fujiwara S, Araki K, Kinjo J, Nohara T, Miyoshi T. Cytotoxic glycosides from Albizia julibrissin. J Nat Prod 1997;60:102-107. doi: 10.1021/ np960556t.

[48] Komori T. Glycosides from Dioscorea bulbifera. Toxicon 1997;35:15311536. doi: 10.1016/S0041-0101(97)00032-9.

[49] Teponno RB, Tapondjou AL, Gatsing D, Djoukeng JD, Abou-Mansour E, Tabacchi $R$, et al. Bafoudiosbulbins $A$, and $B$, two anti-salmonellal clerodane diterpenoids from Dioscorea bulbifera L. var sativa. Phytochemistry 2006; 67:1957-1963. doi: 10.1016/j.phytochem.2006.06.019.

[50] Phua DH, Tsai W], Ger J, Deng JF, Yang CC. Human Melia azedarach poisoning. Clin Toxicol (Phila) 2008;46:1067-1070. doi: 10.1080/15563650802310929.
[51] Zhou YL, Zhang L, Liu W. Protective effect of total glucosides of paeony against acute hepatic injury induced by tripterygium glycosides tablet in mice. Tianjin Journal of Traditional Chinese Medicine 2007;24:61-62.

[52] Rumack BH. AMA handbook of poisonous and injurious plants. JAMA 1986; 255:957-958. doi: 10.1001/jama.1986.03370070111041.

[53] Silva AL, Goto LS, Dinarte AR, Hansen D, Moreira RA, Beltramini LM, et al. Pulchellin, a highly toxic type 2 ribosome-inactivating protein from Abrus pulchellus. Cloning heterologous expression of A-chain and structural studies. FEBS J 2005;272:1201-1210. doi: 10.1111/j.1742-4658.2005. 04545.x.

[54] Wu X, Chen X, Huang Q, Fang D, Li G, Zhang G. Toxicity of raw and processed roots of Polygonum multiflorum. Fitoterapia 2012;83:469-475. doi: 10.1016/j.fitote.2011.12.012.

[55] Ma X, Peng JH, Hu YY. Chinese herbal medicine-induced liver injury. J Clin Transl Hepatol 2014;2:170-175. doi: 10.14218/JCTH.2014.00009.

[56] Larrey D, Faure S. Herbal medicine hepatotoxicity: a new step with development of specific biomarkers. J Hepatol 2011;54:599-601. doi: 10.1016/j. jhep.2010.12.003.

[57] Fu PP, Xia Q, Lin G, Chou MW. Pyrrolizidine alkaloids-genotoxicity, metabolism enzymes, metabolic activation, and mechanisms. Drug Metab Rev 2004;36:1-55. doi: 10.1081/DMR-120028426.

[58] Fu PP, Yang YC, Xia Q, Chou MW, Cui YY, Lin G. Pyrrolizidine alkaloids tumorigenic components in chinese herbal medicines and dietary supplements. J Food Drug Anal 2002;10:198-211.

[59] Wu GL, Yu GY, Chen J. Clinical analysis of hepatic veno-occlusive disease induced by Sedum aizoon. China Journal of Chinese Materia Medica 2008; 33:2402-2404.

[60] Xiong A, Fang L, Yang X, Yang F, Qi M, Kang H, et al. An application of target profiling analyses in the hepatotoxicity assessment of herbal medicines: comparative characteristic fingerprint and bile acid profiling of Senecio vulgaris L. and Senecio scandens Buch.-Ham. Anal Bioanal Chem 2014;406: 7715-7727. doi: 10.1007/s00216-014-8175-z.

[61] Bunchorntavakul C, Reddy KR. Review article: herbal and dietary supplement hepatotoxicity. Aliment Pharmacol Ther 2013;37:3-17. doi: 10.1111/ apt.12109.

[62] Larrey D, Vial T, Pauwels A, Castot A, Biour M, David M, et al. Hepatitis after germander (Teucrium chamaedrys) administration: another instance of herbal medicine hepatotoxicity. Ann Intern Med 1992;117:129-132. doi: 10.7326/0003-4819-117-2-129.

[63] Castot A, Larrey D. Hepatitis observed during a treatment with a drug or tea containing Wild Germander. Evaluation of 26 cases reported to the Regional Centers of Pharmacovigilance. Gastroenterol Clin Biol 1992;16:916-922.

[64] Li C, Liang XS, Li CZ. Sinusoidal obstruction syndrome associated with the ingestion of gynura root. Clin Toxicol (Phila) 2010;48:962-964. doi: 10. 3109/15563650.2010.527851.

[65] Lee SJ, Lee YJ, Park KK. The pathogenesis of drug-induced liver injury. Expert Rev Gastroenterol Hepatol 2016:1-11. doi: 10.1080/17474124. 2016.1196133.

[66] Aithal GP. Pharmacogenetic testing in idiosyncratic drug-induced liver injury: current role in clinical practice. Liver Int 2015;35:1801-1808. doi: 10.1111/liv.12836.

[67] Kleiner DE, Chalasani NP, Lee WM, Fontana RJ, Bonkovsky HL, Watkins PB, et al. Hepatic histological findings in suspected drug-induced liver injury: systematic evaluation and clinical associations. Hepatology 2014;59:661670. doi: 10.1002/hep.26709.

[68] Lewis W, Levine ES, Griniuviene B, Tankersley KO, Colacino JM, Sommadossi JP, et al. Fialuridine and its metabolites inhibit DNA polymerase gamma at sites of multiple adjacent analog incorporation, decrease mtDNA abundance, and cause mitochondrial structural defects in cultured hepatoblasts. Proc Natl Acad Sci U S A 1996;93:3592-3597. doi: 10.1073/ pnas.93.8.3592.

[69] Fisher K, Vuppalanchi R, Saxena R. Drug-induced liver injury. Arch Pathol Lab Med 2015;139:876-887. doi: 10.5858/arpa.2014-0214-RA.

[70] Roth RA, Ganey PE. Intrinsic versus idiosyncratic drug-induced hepatotoxicity-two villains or one? J Pharmacol Exp Ther 2010;332: 692-697. doi: 10.1124/jpet.109.162651.

[71] Mitchell JR, Jollow DJ, Potter WZ, Davis DC, Gillette JR, Brodie BB. Acetaminophen-induced hepatic necrosis. I. Role of drug metabolism. J Pharmacol Exp Ther 1973;187:185-194.

[72] Hinson JA, Roberts DW, James LP. Mechanisms of acetaminophen-induced liver necrosis. Handb Exp Pharmacol 2010:369-405. doi: 10.1007/978-3642-00663-0_12.

[73] Drug-induced liver disease study group, Chinese society of hepatology, Chinese medical association. Guidelines for the management of druginduced liver injury. J. Clin Hepatol 2015;31:1752-1769.

[74] Li L, Jiang W, Wang J. Clinical analysis of 275 cases of acute drug-induced liver disease. Front Med China 2007;1:58-61. doi: 10.1007/s11684-0070012-8. 
[75] Zhu Y, Li YG, Wang Y, Wang LP, Wang JB, Wang RL, et al. Analysis of clinical characteristics in 595 patients with herb-induced liver injury. Zhongguo Zhong Xi Yi Jie He Za Zhi 2016;36:44-48.

[76] Deng WL. A study on toxicity and adverse reactions caused by Lei Gong Teng. Pharmacology and Clinics of Chinese Materia Medica 2001;17:42-47.

[77] Stickel F, Shouval D. Hepatotoxicity of herbal and dietary supplements: an update. Arch Toxicol 2015;89:851-865. doi: 10.1007/s00204-015-1471-3.

[78] Efferth T, Kaina B. Toxicities by herbal medicines with emphasis to traditional Chinese medicine. Curr Drug Metab 2011;12:989-996.

[79] Tu C, Jiang BQ, Zhao YL, Li CY, Li N, Li XF, et al. Comparison of processed and crude Polygoni Multiflori Radix induced rat liver injury and screening for sensitive indicators. Zhongguo Zhong Yao Za Zhi 2015;40:654-660. doi: 10.2174/138920011798062328.

[80] Hu YY, Huang F. Chinese herb and drug-induced liver injury. Zhonghua Gan Zang Bing Za Zhi 2012;20:173-175.

[81] Danan G, Benichou C. Causality assessment of adverse reactions to drugs-I. A novel method based on the conclusions of international consensus meetings: application to drug-induced liver injuries. J Clin Epidemiol 1993;46: 1323-1330. doi: 10.1016/0895-4356(93)90101-6.

[82] Benichou C, Danan G, Flahault A. Causality assessment of adverse reactions to drugs-II. An original model for validation of drug causality assessment methods: case reports with positive rechallenge. J Clin Epidemiol 1993;46: 1331-1336. doi: 10.1016/0895-4356(93)90102-7.

[83] Teschke R, Danan G. Diagnosis and management of drug-induced liver injury (DILI) in patients with pre-existing liver disease. Drug Saf 2016; 39:729-744. doi: 10.1007/s40264-016-0423-z.

[84] Teschke R, Frenzel C, Wolff A, Eickhoff A, Schulze J. Drug induced liver injury: accuracy of diagnosis in published reports. Ann Hepatol 2014;13: 248-255.

[85] Kurth MJ, Yokoi T, Gershwin ME. Halothane-induced hepatitis: paradigm or paradox for drug-induced liver injury. Hepatology 2014;60:1473-1475. doi: 10.1002/hep.27253.

[86] Proctor WR, Chakraborty M, Chea LS, Morrison JC, Berkson JD, Semple K, et al. Eosinophils mediate the pathogenesis of halothane-induced liver injury in mice. Hepatology 2013;57:2026-2036. doi: 10.1002/hep.26196.

[87] Peiris L], Agrawal A, Morris JE, Basnyat PS. Isoflurane hepatitis-induced liver failure: a case report. J Clin Anesth 2012;24:477-479. doi: 10. 1016/j.jclinane.2011.12.004

[88] Abera W, Cheneke W, Abebe G. Incidence of antituberculosis-drug-induced hepatotoxicity and associated risk factors among tuberculosis patients in Dawro Zone, South Ethiopia: A cohort study. Int J Mycobacteriol 2016;5: 14-20. doi: 10.1016/j.ijmyco.2015.10.002.

[89] Elbarbary NS, Ismail EA, Farahat RK, El-Hamamsy M. $\omega-3$ fatty acids as an adjuvant therapy ameliorates methotrexate-induced hepatotoxicity in children and adolescents with acute lymphoblastic leukemia: A randomized placebo-controlled study. Nutrition 2016;32:41-47. doi: 10.1016/j.nut. 2015.06.010.

[90] Teschke R, Frenzel C. Drug induced liver injury: do we still need a routine liver biopsy for diagnosis today?. Ann Hepatol 2013-2014;13:121-126.

[91] Liu FF, Duan XZ, Zang H, Guo XD, Shen LJ, Zhao $P$, et al. Comparative analysis of clinical and hepatic pathologic features in patients with acute drug-induced liver injury caused by traditional Chinese herbs and western medicines. Journal of Practical Hepatology 2013;16:317-319. doi: 10. 3969/j.issn.1672-5069.2013.04.010.

[92] Fontana RJ, Hayashi PH, Gu J, Reddy KR, Barnhart $H$, Watkins PB, et al. Idiosyncratic drug-induced liver injury is associated with substantial morbidity and mortality within 6 months from onset. Gastroenterology 2014; 147:96-108.e4. doi: 10.1053/j.gastro.2014.03.045.

[93] Goldberg DS, Forde KA, Carbonari DM, Lewis JD, Leidl KB, Reddy KR, et al. Population-representative incidence of drug-induced acute liver failure based on an analysis of an integrated health care system. Gastroenterology 2015;148:1353-1361.e3. doi: 10.1053/j.gastro.2015.02.050.

[94] Jeong R, Lee YS, Sohn C, Jeon J, Ahn S, Lim KS. Model for end-stage liver disease score as a predictor of short-term outcome in patients with druginduced liver injury. Scand J Gastroenterol 2015;50:439-446. doi: 10. 3109/00365521.2014.958094.

[95] Sobhonslidsuk A, Poovorawan K, Soonthornworasiri N, Pan-Ngum W, Phaosawasdi $\mathrm{K}$. The incidence, presentation, outcomes, risk of mortality and economic data of drug-induced liver injury from a national database in
Thailand: a population-base study. BMC Gastroenterol 2016;16:135. doi: 10.1186/s12876-016-0550-0.

[96] Robles-Diaz M, Lucena MI, Kaplowitz N, Stephens C, Medina-Cáliz I González-Jimenez $\mathrm{A}$, et al. Use of Hy's law and a new composite algorithm to predict acute liver failure in patients with drug-induced liver injury. Gastroenterology 2014;147:109-118.e5. doi: 10.1053/j.gastro.2014.03.050.

[97] Hillman L, Gottfried M, Whitsett M, Rakela J, Schilsky M, Lee WM, et al. Clinical features and outcomes of complementary and alternative medicine induced acute liver failure and injury. Am J Gastroenterol 2016;111:958965. doi: 10.1038/ajg.2016.114.

[98] Lee WJ, Kim HW, Lee HY, Son CG. Systematic review on herb-induced liver injury in Korea. Food Chem Toxicol 2015;84:47-54. doi: 10.1016/j.fct. 2015.06.004.

[99] Navarro VJ, Barnhart HX, Bonkovsky HL, Davern TJ, Fontana RJ, Hoofnagle $\mathrm{J}$, et al. Herbal and dietary supplement induced hepatotoxicity in the U.S. Gastroenterology 2012;142:S-41. doi: 10.1016/S0016-5085(12)60156-5

[100] Björnsson ES, Hoofnagle JH. Categorization of drugs implicated in causing liver injury: Critical assessment based on published case reports. Hepatology 2016;63:590-603. doi: 10.1002/hep.28323.

[101] Wai CT. Presentation of drug-induced liver injury in Singapore. Singapore Med J 2006;47:116-120.

[102] Bjornsson E, Olsson R. Serious adverse liver reactions associated with herbal weight-loss supplements. J Hepatol 2007;47:295-297; author reply 297-298. doi: 10.1016/j.jhep.2007.05.010.

[103] García-Cortés M, Borraz Y, Lucena MI, Peláez G, Salmerón J, Diago M, et al. Liver injury induced by "natural remedies": an analysis of cases submitted to the Spanish Liver Toxicity Registry. Rev Esp Enferm Dig 2008;100: 688-695.

[104] García-Cortés M, Lucena MI, Pachkoria K, Borraz Y, Hidalgo R, Andrade RJ, et al. Evaluation of naranjo adverse drug reactions probability scale in causality assessment of drug-induced liver injury. Aliment Pharmacol Ther 2008;27:780-789. doi: 10.1111/j.1365-2036.2008.03655.x.

[105] Nin Chau T, Cheung WI, Ngan T, Lin J, Lee KW, Tat Poon W, et al. Causality assessment of herb-induced liver injury using multidisciplinary approach and Roussel Uclaf Causality Assessment Method (RUCAM). Clin Toxico (Phila) 2011;49:34-39. doi: 10.3109/15563650.2010.537662.

[106] Zambrone FAD, Corrêa CL, Amaral LSM. A critical analysis of the hepatotoxicity cases described in the literature related to Herbalife ( $r$ ) products. Braz J Pharm Sci 2015;51:785-796. doi: 10.1590/S1984-82502015000400004.

[107] Teschke R, Eickhoff A. The honolulu liver disease cluster at the medical center: its mysteries and challenges. Int J Mol Sci 2016;17:476. doi: 10. 3390/ijms17040476.

[108] Teschke R, Schulze J, Eickhoff A, Wolff A, Frenzel C. Mysterious Hawaii Liver Disease Case - Naproxen Overdose as Cause Rather than OxyELITE Pro? J Liver Clin Res 2015;2:1013.

[109] Rathi C, Pipaliya N, Patel R, Ingle M, Phadke A, Sawant P. Drug induced liver injury at a tertiary hospital in india: etiology, clinical features and predictors of mortality. Ann Hepatol 2017;16:442-450. doi: 10.5604/16652681. 1235488.

[110] Teschke R, Danan G. Prospective Indian study of DILI with confirmed causality using the roussel uclaf causality assessment method (RUCAM): A report of excellence. Ann Hepatol 2017;16:324-325. doi: 10.5604/ 16652681.1235471

[111] Teschke R, Schwarzenboeck A, Frenzel C, Schulze J, Eickhoff A, Wolff A. The mystery of the Hawaii liver disease cluster in summer 2013: A pragmatic and clinical approach to solve the problem. Ann Hepatol 2016;15:91-109. doi: 10.5604/16652681.1184237.

[112] Yu YC, Mao YM, Chen CW, Chen JJ, Chen J, Cong WM, et al. CSH guidelines for the diagnosis and treatment of drug-induced liver injury. Hepatol Int 2017;11:221-241. doi: 10.1007/s12072-017-9793-2.

[113] Teschke R, Schulze J, Eickhoff A, Danan G. Drug induced liver injury: can biomarkers assist RUCAM in causality assessment? Int J Mol Sci 2017;18: 803. doi: $10.3390 /$ ijms 18040803 .

[114] Shahbaz O, Mahajan S, Lewis JH. Highlights of drug - and herb- induced liver injury in the literature from 2016: how best to translate new information into clinical practice?. Expert Opin Drug Metab Toxicol 2017;13:935951. doi: $10.3390 /$ ijms 18040803 .

[115] Teschke R, Schulze J, Schwarzenboeck A, Eickhoff A, Frenzel C. Herbal hepatotoxicity: suspected cases assessed for alternative causes. Eur J Gastroenterol Hepatol 2013;25:1093-1098. doi: 10.1097/MEG.0b013e3283603e89. 